\title{
Use of Electronic Information Resources by postgraduate students: a case study
}

Peiris, N.D. ${ }^{1}$ and Peiris, B.L. ${ }^{2}$

\begin{abstract}
The vast proliferation of Electronic Information Resources (EIR) has number of significant impacts on the use of print resources. This study describes the results of questionnaire based survey which was conducted to investigate the usage of EIR by postgraduate students of the University of Peradeniya. The study revealed that the majority (77\%) of respondents had used EIR. The majority of postgraduate students use EIR for writing reports and users learned to use EIR by 'self learning' and by trial-anderror. The reading preferences and the use of print and electronic resources varied among users of Postgraduate Institutes/Faculty. Users were not satisfied with the electronic information services offered by the libraries and they strongly believed that currently available EIR were not properly utilized due to the difficulties/problems. Possible suggestions are upgrade facilities to use EIR, subscribe more EIR, and give more publicity to improve the electronic information services at the libraries.
\end{abstract}

Key Words: EIR, EIR usage, information services, Academic Library, Postgraduates

\section{Introduction}

According to the online dictionary of Library and information science (ODLIS, 2004), electronic information can be defined as follows.

"Material consisting of data and/or computer program(s) encoded for reading and manipulation by a computer, by the use of a peripheral device directly connected to the computer, such as a CD-ROM drive, or remotely via a network, such as the Internet The category includes software applications, electronic texts, bibliographic databases, institutional repositories, Web sites, e-books, collections of e-journals, etc. “

\footnotetext{
${ }^{1}$ Senior Assistant Librarian, Agriculture Library, University of Peradeniya, Sri Lanka. E mail: neethad@pdn.ac.lk

2 Senior Lecturer, Faculty of Agriculture, University of Peradeniya, Sri Lanka. E mail: laknathp@pdn.ac.lk
} 
Electronic Information Resources (EIR) are now recognized as being of greatest importance to even small academic libraries. The present supply of information resources is made up of a range of products that may exist in different forms such as CD-ROMs, and resources available on the Internet such as online databases, web pages etc. and they provide libraries with vast resources for their user populations (Gupta, 2011, Zimerman, 2010, Kapoor, 2010).

Thus EIR are vital and they are currently the backbone of any dynamic collection, but most of electronic information resources such as full text databases and electronic books not publicly available free of charge and therefore they are expensive. Today librarians are very much concern about their effective use. It was found from the previous studies (Gupta, 2011, Madhsudhan, 2010, Sheeja, 2010, Kuruppu and Gruber, 2006) EIR are not fully utilized. There are number of Obstacles to use EIR such as lack of IT infrastructure, lack of awareness and poor skills are among the primary reasons for their underutilization. Lack of knowledge about the resources, lack of publicity, insufficient time to use the services and lack of computer training coupled with an inadequate training to use on-line resources and services were other reasons that contributed to the low usage. The usage of EIR depends on variety of factors, such as information searching skills, training and awareness. Information retrieving skills of users are acquired through a variety of ways. Especially in the academic environment, an improved liaison between academic staff and library is likely to increase their knowledge of library resources, which could consequentially lead to high increased usage of EIR by the students (Urquhart and others, 2003).

Users' expectations of libraries and their patterns of Library use are changing as they find more information readily available from the Web (Zimerman, 2010; Gupta, 2011). Previous focus group based studies have shown, the arrival and proliferation of EIR have a number of significant impacts on the use of printed resources. Several authors (Gupta, 2011; Zimerman, 2010; Liu, 2005; Christianson and Aucoin, 2005; Appleton, 2006) have 
Journal of the University Librarians Association, Sri Lanka, Vol. 16, Issue 1, January 2012 demonstrated that reading preferences, perceptions and use of print and EIR vary among different user categories. Most of the users desire to meet their information needs through a mix of print and EIR, while others prefer EIR, to print resources because of hyperlinks to additional resources, enhanced searching capabilities, low cost, availability, and ease of access. However, some users prefer printed versions over electronic.

Several University Libraries in Sri Lanka have initiated and most of them have successfully established electronic information services for their users. The provision and use of electronic information systems in academic libraries have become a critical issue for those working in library services.

Although the University communities have used electronic information, there was limited number of scientific study done in University of Peradeniya, to assess the availability and the usage of electronic information in University libraries. Therefore, specific objectives of this study were:

1. To find out to usage of EIR by postgraduate students of the University of Peradeniya

2. To explore the frequency of use of all EIR

3. To identify the places of access EIR

4. To know the purpose of EIR use

5. To find out the methods of learning to use EIR

6. To ascertain the user attitudes on EIR and user satisfaction on Electronic information services

7. To find out the specific problems that has hindered the EIR usage

8. To suggest measures to improve EIR usage. 
Journal of the University Librarians Association, Sri Lanka, Vol. 16, Issue 1, January 2012

\section{Research Methodology}

\section{Population and Sample}

University of Peradeniya, was selected and the survey method was adopted. The target population belongs to two established postgraduate institutes [Postgraduate Institute of Agriculture ( $P G I A) ~ N=464$ and Postgraduate Institute of Science (PGIS) N=450] and the Postgraduate students enrolled in the faculty of Arts $(\mathrm{N}=522)$ of the University of Peradeniya.

Only the Postgraduate students registered for the Postgraduate degree courses for one academic year were considered since except Ph.Ds and M.Phils, masters courses are running throughout one to one and a half year period. Ten percent (10\%) from the total population was selected and simple random technique was used to select the research sample. The main research tool for data gathering is questionnaires.

\section{Analysis of Data}

Data collected through the questionnaire were analyzed using SAS (Statistical Analysis System). Descriptive statistical analyses were carried out in all instances when necessary. The refined data were also analyzed as percentage and proportion techniques. Results of the analysis were represented in forms of tables, bar charts, pie charts etc. An attitude scale, which was based on Likert method of summated ratings, was analyzed according to the method described by Oppenheim (1992) and Best and Kahn (1992).

\section{Results and Discussion}

\section{Response Analysis}

Out Of the 143 questionnaires sent, highest response rate 97\% (45) was obtained from the students of PGIA while lowest 58.33\% (30) response rate from students of PGIS. Eighty percent $80 \%$ (36) response rate obtained from students from Arts. 


\section{Use and Non-use of Electronic Information Resources (EIR)}

The overall responses showed that the majority of participants (77\%) are using EIR. However $23 \%$ had not used any of the EIR. Results of the Chi-Square test showed there was significant association ( $p=0.001)$ between use of EIR and postgraduate institute / Faculty for postgraduate studies. Postgraduate students from PGIA showed $100 \%$ use of EIR and students from Faculty of Arts showed lowest percentage (16.7\%). Students from PGIS showed $89.8 \%$ use of EIR (Figure 1).

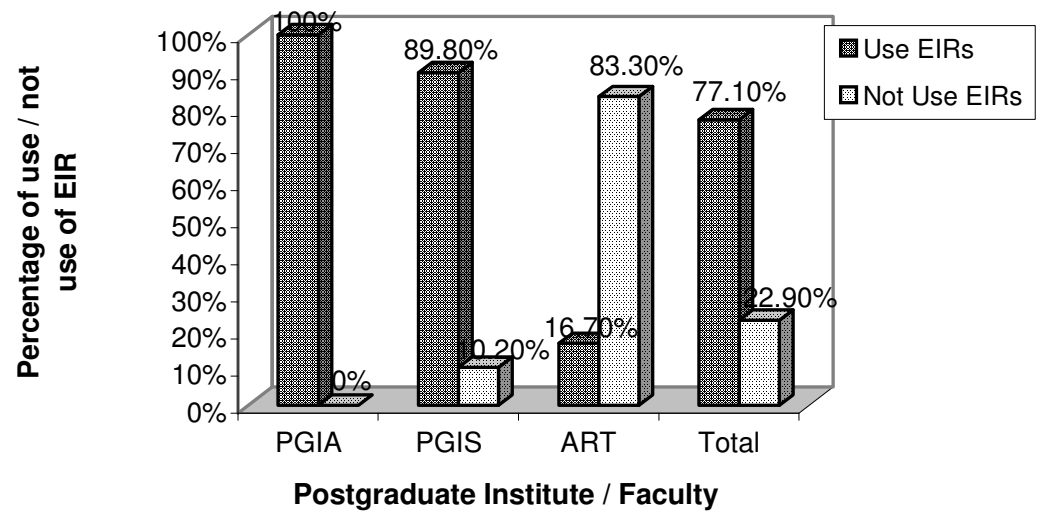

Figure1: Use of EIR by postgraduate students

\section{Availability/Accessibility of EIR}

Results of the analysis on availability/accessibility of EIR at the University of Peradeniya library system for different types of resources implied that the highest accessible resource was the web pages (24\%) and then electronic text (e-mail resorces) (21\%). The lowest accessible resource was the in-house Library databases (7\%) (Figure 2).

The In-house Library databases are still in process of being completed and students could not get the full benefit out of it and therefore the lowest frequency was obtained with respect to the in-house Library databases. 


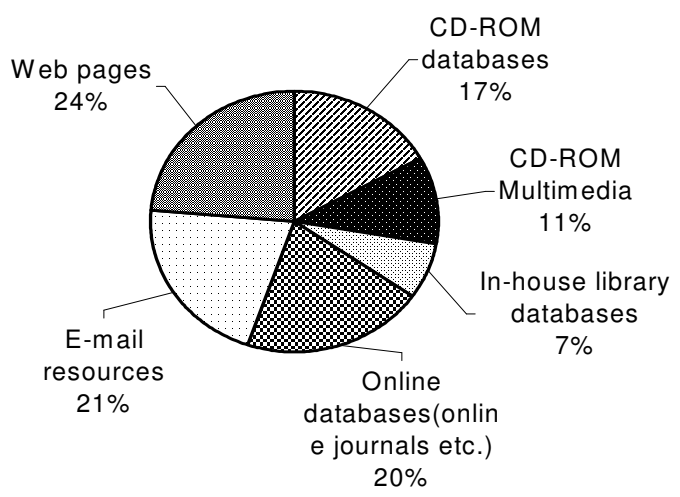

Figure 2: Availability/Accessibility of ElRs for postgraduate students

\section{Frequency of EIR Use}

Frequencies of EIR use were weighted from 06 to 00 (the highest weight was given for the highest frequency of EIR use, i.e. Daily use). Figure 3 displays the frequencies of use of all EIR by the students. It shows that $50 \%$ of Postgraduate students use EIR 'Daily'. One percent (1\%) uses EIR once in six months.

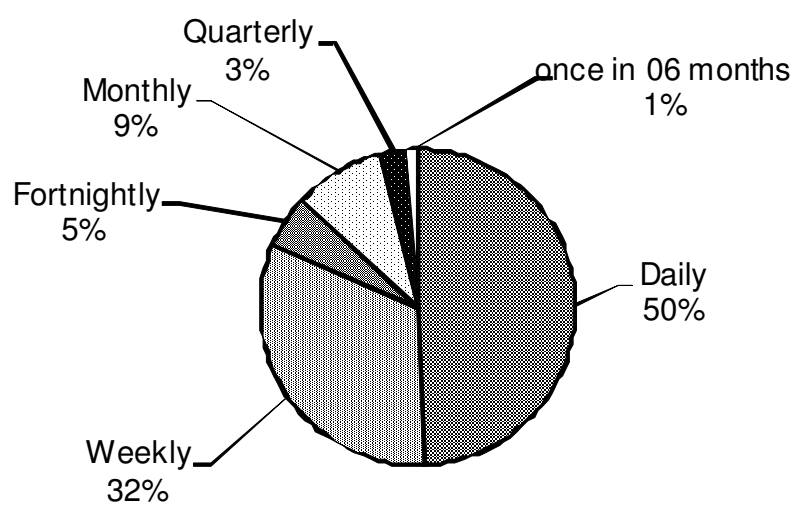

Figure 3: Frequency of use of all EIRs 
Journal of the University Librarians Association, Sri Lanka, Vol. 16, Issue 1, January 2012

Furthermore when analyzed by type of resources, results of the Chi-Square test showed significant association ( $p=0.001$ ) between the frequencies of use and the type of resource only with respect to PGIA and PGIS. It showed that CD-ROM databases, CD-ROM multimedia (video/audio), E-mail resources, and web pages were used daily while other resources such as In-house library databases and on-line databases were used weekly.

\section{Places of Access EIR}

When analysis were made to find out the EIR access points of the respondents, following conclusions can be made with respect to the access points of all EIR.

The Postgraduate students mainly accessed EIR from their home (11.9\%) while 22.5\% from their offices and $7.7 \%$ from their libraries. Other than the libraries of the University of Peradeniya, $2.6 \%$ have accessed EIR from other libraries (Department of Agriculture Library, Open University Library, British Council Library, American center and College Libraries) to use EIR. These libraries might be easy to access from their working places rather than coming to the University of Peradeniya to access EIR. Thirty six percent accessed from 'other places' (i.e. computer units of PGIA and PGIS, departments and Internet cafes). In addition to that they accessed (19.3\%) different types of EIR from the combinations of several access points.

\section{Access to the Library / Libraries of the University of Peradeniya for EIR Use}

Though the users access EIR from different places, data were gathered on which library / libraries the users visited mostly to use EIR in the University of Peradeniya. The highest numbers of respondents of Postgraduate students use the Main Library, which can be ranked as number 01 (Figure 4). Access to different libraries for EIR use, when arranged in the decreasing order, is as follows.

Main > Agriculture / Science $>$ Medical / Veterinary / Engineering $>$ Other 


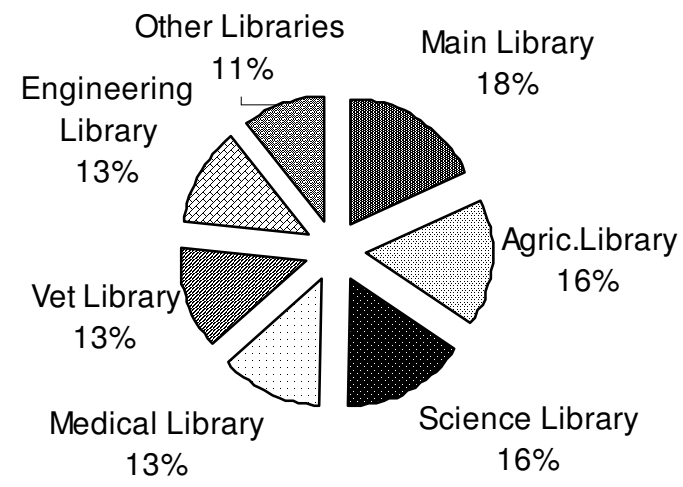

Figure 4: Library/ Libraries access for EIRs Use

Other than the above analysis, frequency of access to all libraries in the University of Peradeniya to use EIR were explored, Majority of the participants (38\%) had used libraries weekly for accessing EIR. Twelve percent use daily while $7 \%$ use fortnightly and $19 \%$ percent participants use libraries monthly (Figure 5).

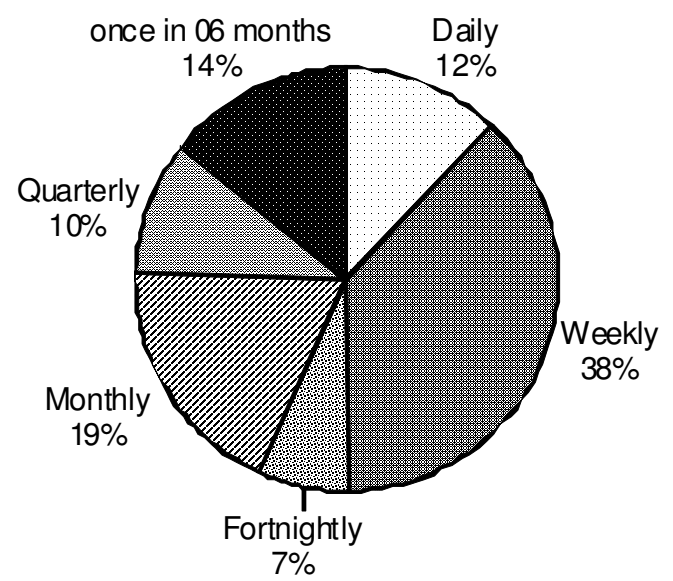

Figure 5: Frequency of use of Library/ Libraries to access EIRs 
Journal of the University Librarians Association, Sri Lanka, Vol. 16, Issue 1, January 2012

Postgraduate students are busy individuals who prefer to work from their offices over the coming to the library. Another reason of low usage of libraries for EIR use was that all on-line databases offered by the libraries are linked to the library web site and these resources can be accessed from other locations within the University premises such as computer units and departments. In-house library databases can also be accessed through the web from anywhere. Due to the limited number of computers available in the libraries, students frequently access the EIR, which are offered by the libraries from different places. So it is worth to note that they virtually access libraries more frequently than visiting the physical library and they never count it as actually visiting the library. Unlike undergraduate students, the majority of Postgraduate students attend the courses part-time. They usually attend lectures during weekends, and they use the libraries only once a week. They actually visit the Library to use other electronic resources like CD-ROM databases, CD-ROM multimedia (video/audio) which is available only within the libraries.

The analysis on relationships among libraries and Postgraduate Institutes / faculty showed that the Postgraduate Institute / Faculty were directly related to the respective Library i.e. higher number of users of PGIA use Agriculture library than other libraries of the University of Peradeniya. Similarly users of PGIS and Faculty of Arts showed higher frequency in the use of their respective libraries, i.e. students of PGIS mostly use Science Library while the students of Arts Faculty frequently use Main Library. The reason might be that all branch libraries of the University of Perdaeniya are special libraries in different subject areas and they mainly cater to their respective faculties and Postgraduate students.

\section{Purposes of EIR Use}

Users use EIR for different purpose(s). As shown in table 1, the highest frequency of use is for writing reports (10.6\%), and secondly, for general use (10.3\%) followed by preparation of assignments (10.2\%). Only 9.9\% use EIR for their research work while $7.3 \%$ for seminar presentations and $5.4 \%$ use it for the preparation of dissertations. 
Table 1: Purposes of EIR use

\begin{tabular}{|c|c|c|}
\hline Purpose & Percentage & Rank \\
\hline ForWriting Reports & $10.6 \%$ & 1 \\
\hline ForGeneral Use & $10.3 \%$ & 2 \\
\hline For preparing assignments & $10.2 \%$ & 3 \\
\hline For Research work & $9.9 \%$ & 4 \\
\hline For Project work & $9.6 \%$ & 5 \\
\hline ForReference & $9 \%$ & 6 \\
\hline For Seminar presentations & $7.3 \%$ & 7 \\
\hline For Up to date knowledge & $6.9 \%$ & 8 \\
\hline For preparation of Dissertations & $5.4 \%$ & 9 \\
\hline For Jobsearch & $5.2 \%$ & 10 \\
\hline ForTeaching & $4.4 \%$ & 11 \\
\hline ForPlanning & $2.9 \%$ & 12 \\
\hline For Bibliographic check & $2.6 \%$ & 13 \\
\hline For Revision & $2.2 \%$ & 14 \\
\hline For someoneelse & $1.6 \%$ & 15 \\
\hline ForShopping & $1.5 \%$ & 16 \\
\hline For Other purposes & $0.4 \%$ & 17 \\
\hline
\end{tabular}

\section{Methods of Learning for EIR Use}

The Information on how users learned to use EIR is given in table 2. Among the different methods of learning, the majority (29.1\%) of users had learned to use EIR by "selflearning through reading manuals". The second highest (26.4\%) method was "by trialand-error". Only $7.7 \%$ learnt from the library staff to use EIR while $1.2 \%$ stated that they were unable to use EIR. 
Journal of the University Librarians Association, Sri Lanka, Vol. 16, Issue 1, January 2012

Table 2: Method of learning for EIR use

\begin{tabular}{l|ll}
\hline Methodof Leaming & Percentage & Rank \\
\hline Self-learning by readingmanuals & $29.1 \%$ & 1 \\
Bytrial-and-error & $26.4 \%$ & 2 \\
Asa part of course work during studies & $17 \%$ & 3 \\
From librarystaff & $7.7 \%$ & 4 \\
Attending special training courses and workshops & $7.1 \%$ & 5 \\
From institutions already using EIR & $6 \%$ & 6 \\
Other (from their colleaguesetc.) & $3.3 \%$ & 7 \\
Notinterested for EIR & $2.2 \%$ & 8 \\
Unableto use & $1.2 \%$ & 9 \\
\hline
\end{tabular}

It was found that although the librarians' in-charge of libraries offer orientation sessions to new comers each year, the student participation in such sessions was poor and hence they may not be aware of the available resources in the libraries. Most of the postgraduate students are not willing to spend much time on library instructions in order to learn information search strategies. Librarians had experienced that students prefer to get the help at the point-of-need. Due to the poor participation in orientation sessions, students have limited understanding about the EIR information searching skills.

Similar to the results of this study, Urquhart and others (2005) too have found that the information retrieving skills are acquired through a variety of routes, peer instruction, surfing and personal experiences, instructions from tutors, library and information science (LIS) induction and training all making an important contribution. 
Journal of the University Librarians Association, Sri Lanka, Vol. 16, Issue 1, January 2012

Kuruppu and Gruber (2006) stated that "some graduate students believed that finding information for their learning and research is something that they ought to know as graduate students or should try to learn by themselves, assuming that it is part of their graduate education". It is also evident from the study conducted by Rehman and Ramzy (2004), the majority of the users preferred self-learning and they believed that it was the most effective mode of learning. Additionally, they found that the training provided by the librarians was another effective mode of learning to use EIR.

The findings of Urquhart and others (2003) also indicated that academic staff plays a key role in encouraging students use EIR effectively. It was also found that substantial percentage of students was getting help from friends or classmates, from academic staff and from librarians for help on the Web. Nevertheless, Kuruppu and Gruber (2006) investigated that teaching staff of the faculties spend limited time or no time in helping the students to acquire the information seeking skills and they expected the graduate students to have information seeking skills. But some staff members have expressed their concern about the lack of knowledge of graduate students' regarding the EIR search tools. It has also found that the language barrier may be a challenge for learning searching skills.

\section{Preference for Use of Electronic and Printed Information Resources}

The proliferation of EIR have already influenced and changed the way of users use the print resources and also the traditional libraries. Students were asked to indicate their preferences for the use of EIR and print information resources.

Figure 6 is a graphical representation of user preferences for EIR and print information resources. The overall responses showed that the majority (38\%) of postgraduate students prefer electronic resources while 35\% prefer print resources. Only $27 \%$ had equal preference for both types of resources. 


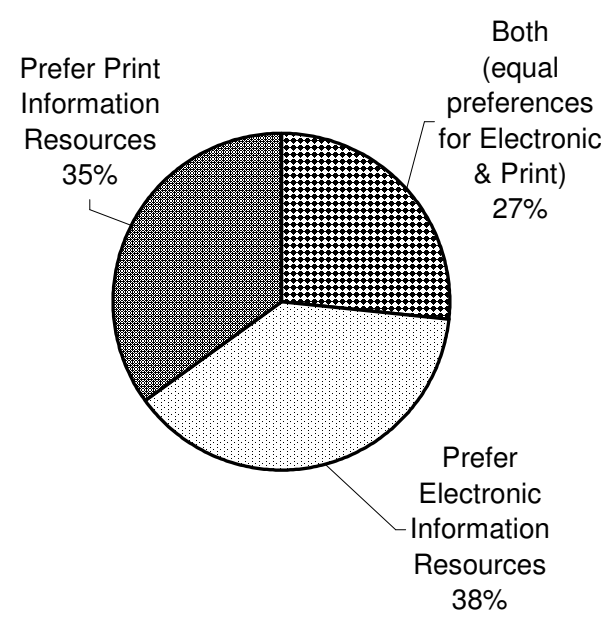

Figure 6: Preferences for information resources

Since Chi-Square test proved that there was a significant association $(p=0.004)$ between preference for types of resources and responses among postgraduate institutes, data were analyzed separately in relation to postgraduate institutes and Faculty.

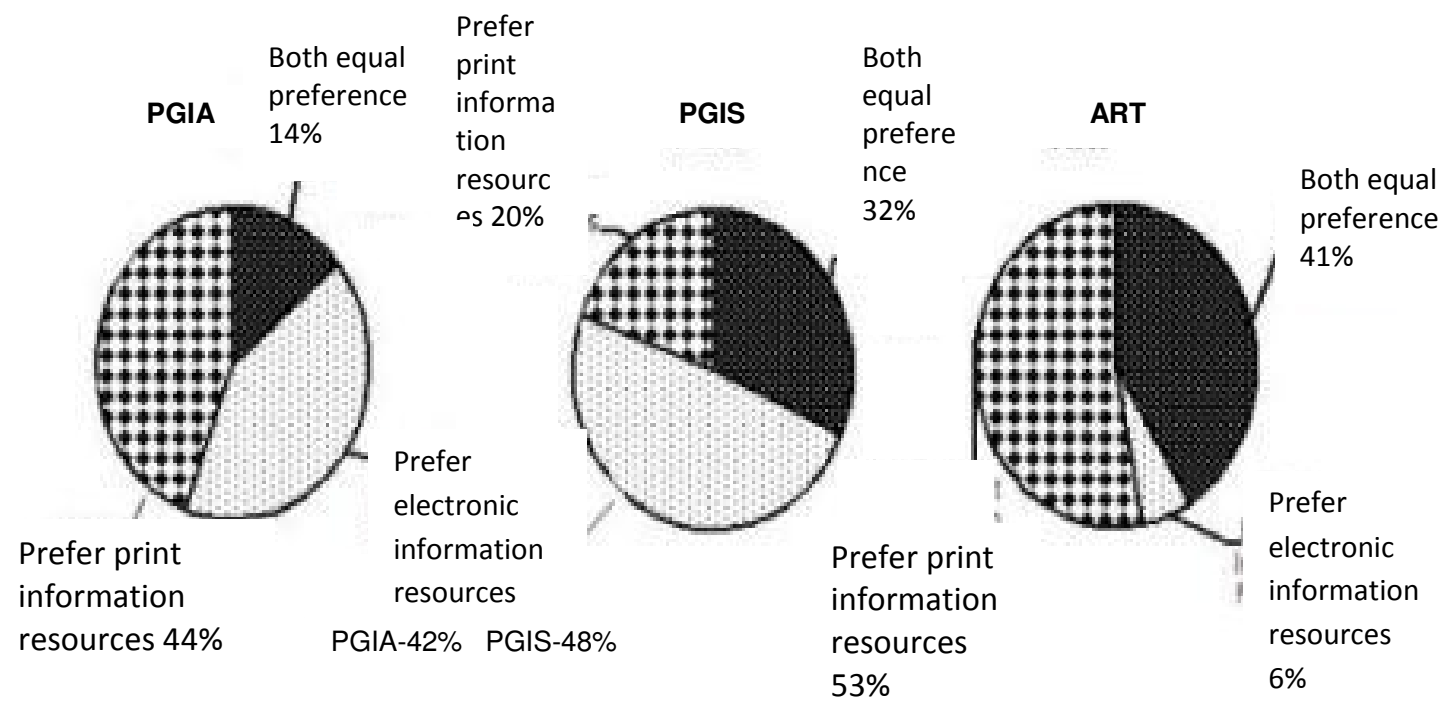

Figure 7: Preferences for information resources by postgraduate institute

Figure / snows the preterences tor intormation resources by postgraquate institutes. The majority of postgraduate students of PGIA (44\%) and participants of Faculty of Arts (53\%) preferred print information resources while postgraduate students of PGIS (48\%) 
Journal of the University Librarians Association, Sri Lanka, Vol. 16, Issue 1, January 2012 preferred electronic resources. Only 20\% participants of PGIS prefer print information resources. The lowest frequency (6\%) of preference for EIR was obtained from postgraduate students of Arts Faculty.

Additionally the users were allowed to freely express their views on reasons for their preferences for information resources types. Sixty-five respondents commented. The majority preferred printed format (18.4\%) and 14.9\% prefer EIR because of the easy of accessing and reading such resources while $10.3 \%$ believed that electronic information can easily be modified / edited / copied / arranged. Eight percent commented that EIR could be accessed from desk at work / can be accessed quickly, 10.4\% expressed that equal preference for both.

In reality, due to the convenience of information access over the quality information resources, users mostly use electronic resources. The results of the previous studied conducted by, Gupta (2011) and Kuruppu and Gruber (2006) also confirmed that students prefer electronic resources because of their speed and convenience. This survey confirmed the previous findings of number of studies conducted over the past years on users' perceptions and preferences for print and electronic resources (Gupta, 2011; Madhusudhan, 2010; Christianson and Aucoin, 2005). Though users use EIR, it was found that most of the postgraduate students prefer to print the articles, which were retrieved electronically, because reading directly on the computer screen is difficult. Therefore students appreciated the easy and the speed of downloading and printing articles they need.

Similar to the results of this study, Liu (2005) in his study explored the extent to which graduate students in a Metropolitan University use print and electronic resources. He explained that the students desire to meet their information needs through a mix of print and electronic resources. Another user study (Gupta, 2011) revealed that a vast majority of graduate students preferred e-journals over print journals and they cited the reasons as links to additional resources, searching capability, currency, availability, and access 
Journal of the University Librarians Association, Sri Lanka, Vol. 16, Issue 1, January 2012

ease. However Melgoza et al. (2002) showed that for scholarly research needs the use of printed materials is still popular among faculty and graduate students.

\section{User Attitudes on EIR}

In addition to the general comments made by the users, respondents were asked to indicate their opinion about the EIR for the given statements and user attitudes were measured in five-point scale; strongly agree (SA), agree (A), undecided (U), disagree (D) and strongly disagree (SD). The percentages of responses calculated from total responses obtained for each statement were grouped as shown in table 3.

\section{Table 3: User attitudes on EIR}

\begin{tabular}{|c|c|c|c|c|c|}
\hline Statement & $S A$ & $A$ & $U$ & $D$ & SD \\
\hline $\begin{array}{l}\text { EIR are not reliable. Their authority is questionable. } \\
\text { Hence it is not advisable to use such resources. }\end{array}$ & $00 \%$ & $17.7 \%$ & $10.4 \%$ & $44.8 \%$ & $27.1 \%$ \\
\hline $\begin{array}{l}\text { EIR are difficult to use. General users are not familiar } \\
\text { to use. Sometime they do not properly utilize. }\end{array}$ & $8.4 \%$ & $23.2 \%$ & $10.5 \%$ & $42.1 \%$ & $15.8 \%$ \\
\hline $\begin{array}{l}\text { There are no full-text on some EIR. Hence one } \\
\text { cannot depend onthese resources. }\end{array}$ & $9.9 \%$ & $51.7 \%$ & $26.3 \%$ & $7.7 \%$ & $4.4 \%$ \\
\hline $\begin{array}{l}\text { Capturing EIR for information searching is difficult, so } \\
\text { one would miss important information if totally rely } \\
\text { on electronic resources. }\end{array}$ & $5.5 \%$ & $45.1 \%$ & $15.4 \%$ & $29.7 \%$ & $4.3 \%$ \\
\hline $\begin{array}{l}\text { Electronic resources are expensive. Some libraries } \\
\text { find difficulties to acquire or access them. As a result } \\
\text { library coverage becomes incomplete. }\end{array}$ & $13.9 \%$ & $61.4 \%$ & $12.9 \%$ & $7.5 \%$ & $4.3 \%$ \\
\hline $\begin{array}{l}\text { Electronic information provides up to date } \\
\text { information compared to other resources. }\end{array}$ & $15.4 \%$ & $63.7 \%$ & $12.1 \%$ & $7.7 \%$ & $1.1 \%$ \\
\hline $\begin{array}{l}\text { EIR can indude many value added services such as } \\
\text { extracted information can be copied, repackaged or } \\
\text { modified and it is very useful for compilation of } \\
\text { reports and articlesetc. }\end{array}$ & $16.1 \%$ & $70.1 \%$ & $6.9 \%$ & $6.9 \%$ & $00 \%$ \\
\hline $\begin{array}{l}\text { Printed resources are better than electronic } \\
\text { resources }\end{array}$ & $2.2 \%$ & $25 \%$ & $42.4 \%$ & $29.3 \%$ & $1.1 \%$ \\
\hline
\end{tabular}




\begin{tabular}{l|lllll}
\hline $\begin{array}{l}\text { Information needs of users are not totally satisfied } \\
\text { with EIR }\end{array}$ & $3.5 \%$ & $69.4 \%$ & $12.9 \%$ & $11.8 \%$ & $2.4 \%$ \\
$\begin{array}{l}\text { EIR facilitate linking to external information } \\
\text { resources from a single access point. }\end{array}$ & $12.1 \%$ & $52.7 \%$ & $25.3 \%$ & $9.9 \%$ & $00 \%$ \\
\hline
\end{tabular}

According to the comments, following facts could be highlighted with respect to the EIR.

Reliability of resources -

Use of EIR -

Availability of EIR -

Searching of EIR -

Cost of EIR -

Up to date of information -

$\underline{\text { Value added services - }}$

Comparison of printed and EIR -

Satisfaction of Information needs -

Linking to other resources -

71.9\% respondents believed that EIR are reliable. $57.9 \%$ expressed their view, as EIR are easy to use.

$61.6 \%$ respondents believed that they couldn't always depend on EIR because no full-text was available on some resources.

$50.6 \%$ felt that searching of information from EIR is difficult.

75.3\% agreed that the EIR are expensive and therefore libraries cannot acquire or cannot fully access them.

majority of respondents (79.1\%) stated that EIR provide up to date information compared to other resources.

$86.2 \%$ believed that EIR have many value added services.

$30.4 \%$ have stated that EIR were better than printed resources while $42.4 \%$ respondents were uncertain about it.

72.9\% expressed that information needs of users are not totally satisfied by EIR.

$64.8 \%$ has given their opinion as EIR facilitate linking to other resources from single access point. 
Journal of the University Librarians Association, Sri Lanka, Vol. 16, Issue 1, January 2012

\section{Users Satisfaction on Electronic Information Services}

User satisfaction on electronic information services, which were provided, by the libraries were tested. It is worth noting that the majority of postgraduate students $(79.3 \%)$ were not satisfied with the electronic information services given by the libraries of the University of Peradeniya. However students satisfied with such services account for only $20.7 \%$.

\section{Difficulties Hindered for EIR Use}

Respondents were asked to give their comments on the users' point of view on what are the difficulties for EIR use. Out of total respondents, $64.6 \%$ respondents made one or more comments. Owing to the wide variety of comments, major addressable problems have been identified (table 4).

Table 4: Difficulties prevailing in the libraries for EIR use

\begin{tabular}{l|l}
\hline Difficulties Prevailing in Libraries for EIR Use & Frequency \\
\hline Lack of equipments (computers etc.) & $18.7 \%$ \\
Lack of EIR & $16.9 \%$ \\
$\begin{array}{l}\text { Lack of awareness of users about availability of EIR/electronic information senvices in the } \\
\text { libraries }\end{array}$ & $12.7 \%$ \\
$\begin{array}{l}\text { Inadequate publicity/lack of guidance/lack of awareness programmes/lack of instructions } \\
\text { Available EIR did not match with users information needs/Access limited/no full-text for all } \\
\text { journals }\end{array}$ & $10.2 \%$ \\
Lackofnecessary funds & $5.9 \%$ \\
Incompetence of users in usingEIR/Lack of knowledge of Tto use EIR & $5.9 \%$ \\
Lackof competent staff/lack of trained staff & $4.2 \%$ \\
Rigid policies/rules and regulations of libraries for library users & $3.4 \%$ \\
No up to date information on EIR/difficulties getting upto date information & $3.4 \%$ \\
Lackof Internetaccess in the libraries & $2.6 \%$ \\
\hline
\end{tabular}


Journal of the University Librarians Association, Sri Lanka, Vol. 16, Issue 1, January 2012

\begin{tabular}{l|l}
\hline Technical difficulties (problems) in Internet access/Low bandwidth of Internet connections & $2.5 \%$ \\
Libraries were not fully computerized/not automated library & $1.7 \%$ \\
No difficulty/satisfactory senvices & $1.7 \%$ \\
Limited library hours to use EIR & $1.7 \%$ \\
Lackof userfriendly services & $0.9 \%$ \\
\hline
\end{tabular}

Out of all comments, the majority (18.7\%) mentioned that lack of equipment is a major difficulty prevailing in the libraries for EIR use and $16.9 \%$ stated that there was not enough EIR while $12.7 \%$ believed that low usage attributed to their lack of awareness of available EIR. Some others (10.2\%) believed that students were not aware of the availability of EIR due to inadequate publicity/ lack of guidance or instructions/lack of awareness programmes. Some users (7.6\%) felt that the available EIR did not match with users information needs/access was limited / there was no full-text for all journals. Students mentioned that the incompetence of users in using EIR or lack of knowledge of IT to use EIR was another difficulty.

The results of the survey also confirmed the previous findings of number of studies which showed that lack of basic requirements for access, hampered the use of EIR. Kebede (2002) confirmed that availability and accessibility of appropriate computer hardware, software, related equipment, adequate user knowledge and skills to interact with the above are essentially needed for EIR use. In addition, the author pointed out that, continuous training programmes for both librarians and end-users are needed for fully utilization of EIR. Results of the study conducted by Crawford and Daye (2000) also found that the lack of IT expertise was one of the major reasons for the low usage of EIR and other reasons were lack of training, opening hours, lack of computers and staffs problems.

It is a widely held view that lack of awareness and poor skills are among the primary reasons for under utilization of EIR (Rehman and Ramzy, 2004; Miller-Francisco, 2003). 
Journal of the University Librarians Association, Sri Lanka, Vol. 16, Issue 1, January 2012

The irrelevant information, incorrect or incomplete indexing and inadequate organization were some other reasons that contributed to the low usage of EIR.

\section{Suggestions to Improve Electronic Information Services}

Respondents have given their suggestions, comments and proposals to improve and provide effective and efficient electronic information services in the libraries. Sixty six percent $(66 \%)$ respondents have made one or more comments. These suggestions were organized under 06 statements as shown in table 5.

Table 5: Suggestions to improve electronic information services

\begin{tabular}{l|l}
\hline Suggestions & Percentage \\
\hline $\begin{array}{l}\text { Should upgrade facilities to use EIR (increase no. of computers with Internet } \\
\text { facilities and increase the bandwidth) }\end{array}$ & $34.7 \%$ \\
$\begin{array}{l}\text { Should give more publicity on availability of EIR, should give more trainings / } \\
\text { guidance/instructions to use EIR } \\
\text { Should have subscribed tomoreEIR(databases with full-textetc.) }\end{array}$ & $33 \%$ \\
Should train the librarystaffforhandlingEIR & $14.9 \%$ \\
Should increase the Libraryopening hours & $9.2 \%$ \\
Should fully automateall libraries & $4.1 \%$ \\
\hline
\end{tabular}

Out of total responses, $34.7 \%$ believed that the libraries of the University of Peradeniya would be able to give a better service to the users if the libraries could increase the facilities by increasing the IT facilities. Thirty three percent (33\%) asked for training to use EIR and give more publicity to aware users on availability of EIR in the system and they strongly believed that it would increase the usage of such resources. Some others (14.9\%) asked for increasing the EIR subscriptions including databases with full-text. Increasing of library opening hours and fully automation of libraries were other suggestions. In this context, it can be concluded that users were keen to see improvement in the electronic information services in the libraries of University of Peradeniya. 
Journal of the University Librarians Association, Sri Lanka, Vol. 16, Issue 1, January 2012

\section{Conclusions}

All types of Electronic Information Resources (EIR) such as CD-ROMs (databases and multimedia), on-line resources (on-line journals and Databases etc.), In-house library databases, E-mail resources and web pages were available in the libraries of the University of Peradeniya and majority of users use EIR.

Out of all EIR defined most accessible / available resources were web pages and e-mail resources while lowest accessible resource was the in-house library databases. Half of the respondents use EIR daily while others uses it weekly, monthly fortnightly, quarterly and once in six month period.

Users have several access points to EIR. Postgraduate students mainly accessed EIR from their home, then from their offices, and from their library. In addition to that they accessed different type of EIR from the combinations of several access points.

Though the users access EIR from all libraries of the University of Peradeniya, they mostly visited the main library. Other than the libraries of University of Peradeniya, users have used external libraries to access EIR. Although postgraduate students use EIR daily, the majority use libraries of the University of Peradeniya weekly for EIR use.

Postgraduate students use EIR for different purposes. They mainly used it for writing reports and secondly for general work followed by preparation of assignments. Moreover they use EIR for their research work, seminar presentations and for dissertation preparation.

Users acquired information skills through a variety of routes. The majority of users had learned to use EIR by self-learning and by trial-and-error.

The majority of postgraduate students prefer electronic resources to print resources. Some have equal preference for both types of resources. However, preference for types of resources varies among postgraduate institutes. The Majority of postgraduate students 
Journal of the University Librarians Association, Sri Lanka, Vol. 16, Issue 1, January 2012

of PGIA and Arts Faculty preferred printed information resources while majority students of PGIS preferred electronic resources.

Lack of equipment is a major difficulty for EIR use. Other problems associated with it were unavailability of current and relevant EIR which were not match with users information needs, limited access and no full-text for all journals. Users were not aware of the availability of EIR due to inadequate publicity and lack of awareness programmes. Incompetence of users in using EIR or lack of knowledge of IT to use EIR was another difficulty.

Users suggested various ways to give effective and efficient electronic information services by the libraries of University of Peradeniya, such as increase the facilities, subscribe more EIR including databases with full-text, increase the number of computers, train library users, more publicity to aware users currently available resources.

\section{Recommendations}

Several University libraries took the initiative and successfully established electronic information services for their users. Identification of problems involving electronic information services will help librarians give better services to their users by overcoming such problems. Also it will help to develop strategies for such type of information resources and services.

Through the introduction of strategic planning and other management initiatives, the library will develop closer ties with clients, thereby taking a leading role in acquiring, accessing and dissemination of electronic information to achieve the academic goals of the University.

The policies should be formulated on EIR especially for purchasing and usage in University of Peradeniya library system. Electronic publications epitomize the problem of the longterm preservation and access to digital resources. They are easily lost, can become 
Journal of the University Librarians Association, Sri Lanka, Vol. 16, Issue 1, January 2012 corrupted, inadvertently deleted, and become inaccessible through changes in technology. Therefore there is an urgent need to develop a solution to address the problems of long-term preservation and access to digital resources.

University should provide more facilities to the users either within the libraries or in some other places, in order to access EIR provided by the libraries.

Since accessibility and connectivity of the Internet play a significant role in the usage of electronic resources, the University authorities should consider improving the quality of the services by modernizing equipments, improving the fiber-optic backbone, which has highest bandwidth with technical support.

It is an essential need that training users and the staff, those who are working in the libraries on EIR. Skills should be improved on access, retrieved and also enlightening them in evaluating of such resources and information. Therefore quality staff development programmes should be introduced.

More awareness programmes to publicize the currently available resources in the libraries by means of user education programmes, leaflets, posters and notices should be introduced by the libraries.

Fully automation of the University libraries should be done as early as possible in order to give effective and efficient services to the users.

Also the library awareness programmes should be integrate with the curricular of the University and it will pave the way to use the available resources are in the libraries effectively.

The authorities of the libraries should carry out frequent analyses and investigations by the survey on usage of electronic resources and problems regarding such resources. 
Journal of the University Librarians Association, Sri Lanka, Vol. 16, Issue 1, January 2012

The proliferation of EIR have already influenced and changed the way of users use print resources and traditional libraries. And it has also sparked a new wave on the perception and preferences of print and electronic resources. Also the electronic environment has created significant changes in the roles of the librarians. Librarians must keep abreast with constantly advancing technology, and also with the new methods of organizing, storing, and retrieving information. Librarians' traditional expertise with print material has to be expanded in order to include knowledge of electronic information. Therefore, the attitudes of the users and the librarians towards the electronic information should be changed.

\section{References}

Appleton, L. (2006). Perceptions of electronic library resources in further education. The Electronic Library, 24(5), 619-633.

Best, J.W. and Kahn, J.V. (1992). Research in education. Prentice Hall of India, New Delhi.

Christianson, M. and Aucoin, M. (2005). Electronic or print books: which are used? Library Collections, Acquisitions \& Technical Services, 29, 71-81.

Crawford, J.G. and Daye, A. (2000). A survey of the use of electronic services at Glagow Caledonian University library. The Electronic Library, 18(4), 255-265.

Gupta, D.K. (2011). Use pattern of print and electronic journals at the Kurukshetra University, India. Program: electronic library and information systems. 45 (2), 213230.

Kapoor, K. (2010). Print and electronic resources: usage statistics at Guru Gobind Sing Indraprasta University library. Program: electronic library and information systems.44 (1) 59-68.

Kebede, C. (2002). the changing information needs of users in electronic information environments. The Electronic Library, 20 (1), 14-21.

Kuruppu, P.U. and Gruber, A.M. (2006) Understanding the information needs of academic scholars in agricultural and biological sciences. Journal of Academic Librarianship, 32 (6), 609623.

Liu, Z. (2005). Print vs. electronic resources: A study of user perceptions, preferences and use. Information Processing and management. 42, 583-592. 
Journal of the University Librarians Association, Sri Lanka, Vol. 16, Issue 1, January 2012

Madhusudhan, M. (2010). Use of electronic resources by research scholars of Kurukshetra University. The Electronic Library, 28 (4), 492-506.

Melgoza, P., Mennel, P.A. and Gyeszly, S.D. (2002). Information overload. Collection Building, 21 (1), 32-42.

Miller-Francisco, E. (2003). Managing electronic resources in a time shrinking budgets. Library Collections, Acquisitions \& Technical Services, 27, 507-512.

ODLIS: Online Dictionary of Library and Information Science (2004). Retrieved from <http://web pages.abc-clio.com/ODLIS/odlis_h.aspx> (December 2011)

Oppenheim, A.N. (1992). Questionnaire Design, Interviewing and Attitude Measurement. New Edition. London, Printer Publishers. 303p.

Rehman, S. Ur and Ramzy, V. (2004). Awareness and use of electronic information resources at the health sciences center of Kuwait University. Library Review 53 (3), 15-156

Sheeja, N.K (2010). Surveying scholars' perceptions of electronic environments: A case study of University libraries in Kerala (India). The International Information \& Library Review. 42 , 262-268.

Urquhart, C., Thomas, R., Armstrong, C., Fenton, R., Lonsdale, R., Spink, S. and Yeoman, A. (2003). Uptake and use of electronic information services: trends in UK higher education from the JUSTEIS project. Program: Electronic library and Information Systems, 37 (3), 168-180.

Urquhart, C., Thomas, R., Spink, S., Fenton, R., Yeoman, A., Lonsdale, R., Armstrong, C., Banwell, L., Ray, K., Coulson, G. and Rowley, J. (2005). Student use of electronic information services in further education. International Journal of Information Management, 25, 347-362.

Zimerman, M. (2010). Periodicals: print or electronic? New Library World. 111 (9/10) 426433. 